\section{Assessment and determinants of aesthetic discomfort in hand osteoarthritis}

The objectives of the present study are to assess the magnitude and the determinants of aesthetic discomfort in hand osteoarthritis $(\mathrm{HOA})^{12}$ in 203 consecutive outpatients attending a tertiary care centre (University Hospital) specialised in bone and cartilage metabolism and diagnosed with HOA. ${ }^{3}$ All distal and proximal interphalangeal joints and thumb base were assessed for painful and tender joints and presence of nodes. A total of $90.1 \%$ of the subjects were women. Patient's global assessment of pain used a $100 \mathrm{~mm}(0-100)$ Visual Analog Scale (VAS). The patients rated their aesthetic discomfort related to HOA on a $100 \mathrm{~mm}$ VAS $(0-100)$ and on a Likert scale (0-7) used for the assessment of aesthetic damage in Forensic (ie, medicolegal assessment) medicine (ranging from $0=$ no damage to $7=$ very important damage). Pain, stiffness and function were assessed using Australian Canadian Osteoarthritis Hand Index (AUSCAN). Functional disability was measured using Functional Index for HOA. Health-related quality of life (HRQoL) was assessed by the Short Form 12 and by EuroQol. Psychological status was measured by Hospital Anxiety and Depression scale. Radiographs were assessed following Verbruggen and Veys ${ }^{4}$ and Kellgren and Lawrence. ${ }^{5}$ We assessed the presence of erosive osteoarthritis (OA) (ie, at least one joint at the erosive or remodelled phase, ${ }^{4}$ and the number of severely affected joints). ${ }^{5}$ Quantitative variables were expressed by median and IQR (Q1Q3) due to skewed distributions. Qualitative variables were expressed by number and percentage. In the univariate analysis, association between aesthetic discomfort (VAS), or the magnitude of the aesthetic damage (medicolegal scale), and qualitative parameters was assessed by means of a Student's $t$ test or Kruskal-Wallis test, while correlations with quantitative parameters were tested using Pearson or Spearman rank correlation. All parameters with $\mathrm{p}<0.25$ in the univariate analysis were combined into a multiple regression with stepwise procedure to account for potential confounders. Results were considered statistically significant at the $5 \%$ level $(\mathrm{p}<0.05)$.

The median age of the population was 69.1 years (Q1: 61.9Q3: 75.6). A total of $6.9 \%, 40.4 \%, 22.2 \%$ and $30.5 \%$ of the subjects reported a duration since the onset of symptoms of HOA of $<1,1$ to 5,6 to 10 and $>10$ years, respectively. The median score of hand pain at rest on a $100 \mathrm{~mm}$ VAS was 50.0 (29.0-59.0). The median number of painful joints at rest and at pressure was $1.0(0.0-4.0)$ and $5.0(2.0-10.0)$, respectively. Eighty-seven (42.9\%) subjects presented with erosive HOA.

The median value of the aesthetic discomfort on the $100 \mathrm{~mm}$ VAS was $35.0(6.0-59.0)$. On the medicolegal scale, the median damage was rated at $3.0(1.0-4.0)$ corresponding to a 'moderate' level. After a stepwise analysis, the parameters correlated to the aesthetic discomfort and damage were the number of joints with severe HOA, the AUSCAN score, the female gender, the presence of erosive HOA and the duration of OA. In conclusion, the aesthetic discomfort reflects a significant concern for patients with HOA. The association of erosive HOA and increased aesthetic discomfort is in close agreement with several publications showing that the subset of patients developing erosive HOA usually face a higher clinical burden. ${ }^{6-8}$ It should be noted that erosive OA is over-represented in our population, maybe a consequence of the process of recruitment. This should be considered when extrapolating our results to the general HOA population.

\section{A Neuprez, ${ }^{1} 0$ Bruyère, ${ }^{1} \mathrm{~N}$ Dardenne, ${ }^{1} \mathrm{~S}$ Distèche, ${ }^{1}$ E Maheu, ${ }^{2}$ N Burlet, ${ }^{1}$ P D'Hooghe, ${ }^{3} \mathrm{~J}$ Y Reginster ${ }^{1}$ \\ ${ }^{1}$ Department of Public Health, Epidemiology and Health Economics, University of Liège, Liège, Belgium \\ ${ }^{2}$ Department of Rheumatology, AP-HP, St. Antoine Hospital, Paris, France ${ }^{3}$ Department of Orthopaedics and Sports Medicine, Aspetar Hospital, Doha, Qatar}

Correspondence to Professor J Y Reginster, Department of Public Health, Epidemiology and Health Economics, University of Liege, Liege 4020, Belgium; jyreginster@ulg.ac.be

Contributors All authors contributed to the study design, interpretation of data and preparation of the manuscript. ND was responsible for the statistical analyses. SD and AN were in charge of the patients assessments and X-Rays readings.

Competing interests None declared.

Patient consent Obtained.

Provenance and peer review Not commissioned; externally peer reviewed.
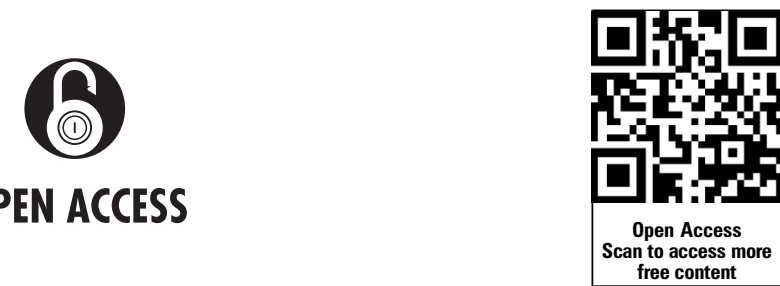

Open Access This is an Open Access article distributed in accordance with the Creative Commons Attribution Non Commercial (CC BY-NC 4.0) license, which permits others to distribute, remix, adapt, build upon this work non-commercially, and license their derivative works on different terms, provided the original work is properly cited and the use is non-commercial. See: http://creativecommons.org/ licenses/by-nc/4.0/

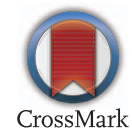

To cite Neuprez A, Bruyère O, Dardenne N, et al. Ann Rheum Dis 2015;74:1942.

Received 2 April 2015

Revised 11 June 2015

Accepted 14 July 2015

Published Online First 4 August 2015

Ann Rheum Dis 2015;74:1942. doi:10.1136/annrheumdis-2015-207718

\section{REFERENCES}

1 Michon M, Maheu E, Berenbaum F. Assessing health-related quality of life in hand osteoarthritis: a litterature review. Ann Rheum Dis 2011;70:921-8.

2 Hodkinson B, Maheu E, Michon M, et al. Assessment and determinants of aesthetic discomfort in hand osteoarthritis. Ann Rheum Dis 2012;71:45-9.

3 Altman R, Alarcon G, Appelrouth D, et al. The American College of Rheumatology criteria for the classification and reporting of osteoarthritis of the hand. Arthritis Rheum 1990;33:1601-10.

4 Verbruggen G, Veys EM. Numerical scoring systems for the anatomic evolution of osteoarthritis of the finger joints. Arthritis Rheum 1996;39:308-20.

5 Kellgren JH, Lawrence JS. Radiological assessment of osteo-arthrosis. Ann Rheum Dis 1957;16:494-502.

6 Kwok WY, Kloppenburg M, Rosendaal FR, et al. Erosive hand osteoarthritis: its prevalence and clinical impact in the general population and symptomatic hand osteoarthritis. Ann Rheum Dis 2011;70:1238-42.

7 Bijsterbosch J, Watt I, Meulenbelt I, et al. Clinical burden of erosive hand osteoarthritis and its relationship to nodes. Ann Rheum Dis 2010;69:1784-8.

8 Marshall M, Nicholls E, Kwok WY, et al. Erosive osteoarthritis: a more severe form of radiographic hand osteoarthritis rather than a distinct entity? Ann Rheum Dis 2015;74:136-41. 